\title{
Jogo de contar histórias: o uso de técnicas de criação de narrativas colaborativas em sala de aula
}

Tatiane Schuster - UNISINOS - tatianeschuster@ gmail.com

Tiago Ricciardi Correa Lopes - UNISINOS - tiagorclopes@gmail.com

\section{Resumo}

O artigo relata o processo de desenvolvimento e aplicação de uma técnica de criação de narrativas colaborativas com alunos de ensino fundamental e médio, tendo como objetivo principal prestar uma contribuição ao debate sobre o uso de elementos lúdicos em atividades de ensino-aprendizagem. Os procedimentos metodológicos incluem: pesquisa de sistemas de jogos de interpretação de papéis, planejamento e aplicação de uma técnica de criação coletiva de histórias com alunos de ensino fundamental e médio. A discussão é realizada com base nos resultados das experiências de aplicação da técnica, encaminhando propostas de reformulação e ajustes em sua mecânica de funcionamento.

\section{Palavras-chave}

jogos de interpretação de papeis, educação, narrativa

\begin{abstract}
The article describes the process of development and application of a technique of creating collaborative stories technique with group of students from elementary and high school. The main objective is to provide a contribution to the debate about the use of playful elements in order to promote greater students engagement in teaching and learning. The methodological procedures include: role-playing games systems research; planning a technical collective creation stories and the application of the technique with groups of students from elementary and high school. The discussion is taking place based on the results obtained from the experiences of application of the technique, submitting proposals to overhaul and adjustments in its mechanical operation.
\end{abstract}

\section{Keywords}

role playing games, education, narrative

\section{Introdução}

Uma das principais questões que acompanham o cotidiano de professores de todas as áreas diz respeito ao desafio de como gerar motivação em atividades de ensinoaprendizagem. Autores como Kishimoto (1994), integram uma corrente de pensamento que encontra no uso de jogos em sala de aula um recurso eficiente para captar a atenção, promover o engajamento e estimular a criatividade dos alunos.

Dentre as possibilidades de aplicação de jogos em atividades de ensinoaprendizagem, destacamos, neste artigo, a apropriação e uso de dinâmicas de jogos de interpretação ${ }^{1}$ em experiências de construção colaborativa de textos em sala de aula. $\mathrm{O}$ texto é apresentado na forma de relato e descreve o processo de formulação e aplicação de uma técnica de criação de narrativas colaborativas com alunos da Colégio Estadual Dr. Wolfram Metzler ${ }^{2}$. Esta atividade foi promovida por alunos do curso de graduação em Letras da Universidade do Vale do Rio dos Sinos (UNISINOS), participantes do Programa Institucional de Bolsas de Iniciação à Docência (PIBID), com o apoio de 
integrantes do Grupo de Estudos em ${ }^{2}$

Narrativas Interativas (GENI), dessa mesma instituição. ${ }^{3}$

O texto está dividido em quatro partes. Na primeira parte, introduzimos o debate sobre o uso de elementos e dinâmicas de jogos de interpretação em sala de aula, recuperando algumas das principais contribuições de autores que se dedicaram a pensar sobre esse assunto ao longo da última década no contexto do ensino brasileiro. Em seguida, relatamos o processo de desenvolvimento de uma técnica de criação de narrativas colaborativas a partir da adaptação dos elementos da mecânica do roleplaying game $e^{4}$ (RPG) Violentina. Na terceira parte, relatamos o processo de aplicação dessa técnica com um grupo de alunos de uma escola estadual de ensino médio, destacando os pontos positivos e negativos dessa experiência para, em seguida, apresentar as alterações e ajustes realizados sobre a técnica a partir dos resultados alcançados. A quarta e última parte apresenta os resultados obtidos na segunda vez em que a técnica foi aplicada, encaminhando o fechamento do texto com algumas considerações resultantes dessas duas ocasiões em que testamos uma proposta de criação de narrativas colaborativas em sala de aula.

\section{Técnicas de narrativas colaborativas}

O emprego de técnicas de criação de narrativas em sala de aula que utilizam princípios e elementos de RPGs não constitui prática recente em território nacional. Por volta do final dos anos noventa e início dos anos dois mil, surgiram diversas publicações e eventos que abordavam o uso dessa modalidade de jogos aplicados à educação. Desde o seminal estudo de Sônia Rodrigues ${ }^{5}$, que promovia uma aproximação entre os RPGs e os gêneros literários, iniciativas sobre o uso desse estilo de jogo no contexto escolar foram debatidas em diversos contextos, com destaque para eventos pioneiros nessa área, como o I Simpósio de RPG e Educação ${ }^{6}$, ocorrido em 2002, em São Paulo. Desde então, o uso de RPG em atividades de ensino-aprendizagem vem pautando os estudos de diversos pesquisadores.

Neste artigo, não haveria espaço suficiente para listarmos todos os congressos, autores e publicações que contribuíram com o debate em torno desse tema mapeamentos desse tipo já foram realizados, com muita competência, em estudos como o apresentado por Grando e Tarouco (2008). Portanto, nesta seção, nos limitaremos a destacar algumas experiências realizadas nessa área, que serviram de inspiração para a experiência aqui apresentada de aplicação de uma técnica de narrativas colaborativas com alunos de ensino fundamental e médio, desenvolvida com base na análise e adequação da mecânica de um jogo desse estilo.

Historicamente, em um primeiro momento, as atividades com narrativas colaborativas em sala de aula se restringiam somente ao emprego das técnicas e regras oriundas de jogos de RPG comerciais, sem nenhum tipo de preparação que visasse adequá-las para o contexto escolar. Portanto, tais experiências demonstravam limitações em relação às possibilidades de uso desses jogos como recursos de sala de aula, uma vez que os sistemas tradicionais de RPG não se destinavam ao ensino formal. Assim, com o passar do tempo, uma nova categoria de jogos surgiu, os chamados RPGs didáticos, que tomavam como base os sistemas tradicionais e os adaptavam para contextos específicos de ensino-aprendizagem.

Tais propostas de implementação das mecânicas de jogos de RPG em sala de aula apresentam, de modo geral, inspiração em teorias construtivistas de educação, que, em síntese, são baseadas na ideia de que a produção do conhecimento é um processo que ocorre através da participação ativa do aluno (Vygotsky, 1994). Seguindo essa linha de pensamento, Pereira (2008) apresenta a pedagogia da autoria, baseada nos 


\section{3}

pressupostos estabelecidos no conceito de

pedagogia da autonomia, de Paulo Freire (2006), que incentiva métodos educacionais em que docentes e discentes assumem papeis de protagonismo no processo de construção de conhecimento. Nesse sentido, sua proposta busca extrair dos RPGs um método de criação de narrativas coletivas para fins educacionais.

Relatos sobre a aplicação de técnicas de ensino-aprendizagem que tomam de empréstimo recursos dos jogos de RPG (sejam estes digitais ou não) apresentam motivações e finalidades variadas. Azevedo (2007) relata experiências de aplicação de jogos de RPG em aulas de História: para ele, durante a realização dos laboratórios de criação, conforme a denominação empregada pelo autor, os alunos são conduzidos a interagirem e a tomarem decisões dentro de um ambiente temático propiciado pelo jogo, o que os auxilia a compreender não só fatos tidos como historicamente importantes, mas também, e acima de tudo, a desenvolver uma aproximação emocional sobre tais momentos históricos. Para Azevedo, o aluno que participa de uma experiência de RPG "sente" a história quando precisa lidar com as consequências emocionais das suas decisões, criando vínculos afetivos que contribuem para o processo de aprendizagem dos conteúdos que lhes são apresentados através desse meio.

Outras propostas de uso de RPG em sala de aula incluem o ensino de línguas, como no trabalho relatado por Silveira (2004), em que o autor, na função de professor, criou uma situação hipotética como forma de envolver os alunos em um ambiente narrativo: após terem ganhado um concurso, eles estariam participando de uma viagem de férias, nos Estados Unidos. Durante o jogo, os alunos deveriam realizar várias atividades em que o domínio do idioma em língua inglesa seria fundamental, como, por exemplo, interagir com a tripulação do avião em que estariam viajando, responder às perguntas do fiscal da alfândega, encontrar e conversar com a pessoa responsável por buscá-los no aeroporto etc. Ainda, em alguns momentos da história, os alunos deveriam acessar materiais diversos com conteúdos em inglês: numa determinada situação, um bilhete era encontrado, já em outra, uma fita de cassete trazia mensagens que ajudavam os alunos a avançar na história.

Bettocchi e Pereira (2008) também relatam uma experiência realizada com alunos de ensino médio de um colégio estadual do Rio de Janeiro, que teve como objetivo investigar a utilização de histórias interativas em suporte impresso como estímulo à leitura e escrita. Nesse mesmo estudo, os autores exploram o conceito de metajogo, que se refere às atividades relacionadas ao jogo que acontecem fora do período em que se está jogando. No caso dos RPGs, o metajogo ocorre, por exemplo, nas pesquisas de referência que cada jogador desenvolve para construção do seu personagem, nas conversas presenciais e à distância (via e-mail e fóruns, por exemplo), em diários mantidos pelos jogadores com registros das sessões de jogos etc. Percebendo a importância deste conceito para o processo de aprendizagem, os autores procuraram criar estratégias para ampliar o processo de metajogo nas atividades de RPG realizadas em sala de aula. Assim, além das pesquisas de referência, realizadas sobre o material fornecido pelos professores, foi solicitado aos alunos outras produções relacionadas à experiência de jogo - por exemplo, um dossiê de cada personagem, com um relato das aventuras vividas, certidão de nascimento e perfil. Os produtos resultantes dessas atividades foram, posteriormente, incorporados ao material de referência do jogo, tornando mais rica a experiência de outros grupos que viriam a ter contato com essa dinâmica.

Tendo essas experiências como referência, procuramos encaminhar algumas contribuições para a produção de textos em sala de aula, oferecendo uma proposta de atividade que estimule a capacidade criativa dos alunos e que também promova reflexão 
4

crítica sobre os conteúdos trabalhados em

sala de aula. Nas próximas seções, apresentamos o relato de um processo de formulação e aperfeiçoamento de uma técnica de criação de narrativas colaborativas aplicada a contextos de ensino-aprendizagem.

\section{Procedimentos metodológicos: planejamento e aplicação do jogo de contar histórias}

Nesta seção, apresentamos o processo de desenvolvimento e aplicação da técnica de criação de narrativas colaborativas "jogo de contar histórias"7 com um grupo de alunos do colégio estadual Dr. Wolfram Metzler. Conforme mencionamos na introdução deste texto, essa atividade foi realizada por alunos do curso de graduação em Letras da UNISINOS, em parceria com o Grupo de Estudos em Narrativas Interativas $(\mathrm{GENI})^{8}$, responsável pela concepção e planejamento do jogo de contar histórias. Portanto, antes de avançarmos para a descrição da técnica em si, apresentamos, brevemente, as etapas que conduziram o seu processo de desenvolvimento.

Desde 2010, o Grupo de Estudos em Narrativas Interativas vem estudando e projetando técnicas para criação de narrativas colaborativas ${ }^{9}$. Algumas dessas técnicas foram planejadas a partir da análise de dinâmicas de jogos de interpretação, sobretudo tomando-se como base os sistemas de regras de jogos de RPG. Contudo, devido ao nível de complexidade que tais sistemas de regra apresentam, o processo de adaptação da mecânica do jogo para atividades de sala de aula nem sempre é uma tarefa fácil, visto que exigem um nível de concentração e esforço de aprendizado por parte dos alunos difícil de ser alcançado. Além disso, uma das principais características desses jogos é a centralização das atividades do jogo em torno da figura do mestre, sendo que, na maior parte dos relatos de aplicação de técnicas de RPG em atividades de ensinoaprendizagem, a função de mestre é exercida pelo professor.

O problema de ter o professor como único mestre é que o controle da atividade se torna mais difícil na medida em que o grupo de alunos aumenta de tamanho. Uma solução para esse problema encontrada por Bettochi e Pereira (2008) foi treinar alguns alunos para atuarem como mestres durantes as sessões de jogo. Cada aluno-mestre ficava então responsável por conduzir as atividades de jogo de um grupo pequeno de alunos, com cerca de cinco integrantes.

Segundo relato dos autores, a opção pela capacitação de alunos para a função de mestre resultou eficaz, porém, de acordo com nosso ponto de vista, essa estratégia implica em algumas limitações. A primeira delas diz respeito ao tempo necessário para treinar os alunos para a função de mestre das sessões de jogo - cinco encontros em horário extra-classe. Essa preparação exige um esforço de logística e empenho por parte de professores e alunos que praticamente inviabiliza a sua realização na maioria dos casos.

Ainda, uma outra solução para o problema de aplicar técnicas de RPG em turmas grandes é dividi-las em grupos menores, com cada um ficando responsável por controlar um personagem ao longo do jogo. A questão, porém, é que essa estratégia apresenta o risco de que parte dos alunos perca o interesse na atividade, pois, inevitavelmente, enquanto alguns poucos se mostram mais engajados e por conta disso passam a assumir uma posição de liderança no controle das ações do personagem de seu grupo, os outros acabam ficando desestimulados e se dispersam ao longo do jogo.

Tendo em vista as dificuldades apresentadas no processo de adaptação de RPGs para o ambiente de sala de aula, o GENI passou a buscar outras alternativas de jogos que também explorassem o potencial de narração de histórias em grupo. Assim, dentre os tipos de jogos com essas características encontrados pelo grupo, destacamos uma 
modalidade que apresenta como 5

característica operar a partir da ideia de narração compartilhada da história, ou seja, abrindo mão da figura do mestre como principal narrador dos eventos que acontecem durante a sessão de jogo. Alguns títulos que integram esse conjunto de jogos de RPG que apresentam técnicas de compartilhamento da função narrativa são Três corvos, três homens mortos; Fiasco e O jogo dos espíritos. ${ }^{10}$

Além dos casos citados, adotamos como parâmetro para desenvolvimento da técnica de jogo de contar histórias o RPG Violentina ${ }^{11}$, um projeto independente, de autoria de Eduardo Caetano, que tem como característica principal o estímulo à criação de histórias de ação e violência, inspiradas nos estilos narrativos de filmes como os dirigidos por Quentin Tarantino e Guy Ritchie.

Uma das principais diferenças de Violentina em relação aos RPGs tradicionais é o tempo de preparação para iniciar o jogo, bem menor do que na maioria dos jogos nesse estilo, visto que o jogo dispensa a elaboração de fichas de personagens, assim como de pesquisas prévias de referências para compor o ambiente em que a história acontece. Também o sistema de regras do jogo é bastante simples, facilitando a compreensão até mesmo por parte de jogadores que nunca tiveram contato com RPG. Além de papel e caneta, são necessários dois baralhos de cartas tradicionais que orientam a construção dos personagens e da escolha de alguns elementos que integram a trama narrativa.

Após ter sido estudado pelo GENI, esse jogo foi adaptado para o contexto escolar. Ao longo desse processo, o objetivo dos integrantes do grupo foi a criação de uma versão ainda mais simples que a original, aproveitando parte da mecânica e alguns de seus elementos. Quanto mais simples fosse o jogo, mais rápido e eficiente seria a compreensão de suas regras, o que, teoricamente, aumentaria as chances de que alunos de diferentes faixas etárias pudessem jogá-lo. A simplificação permitiria também "abrir" o jogo para que praticamente qualquer tema pudesse ser utilizado - e não apenas os temas que pautam as sessões de jogo de Violentina, voltados para o universo de filmes de ação e violência.

A seguir, explicamos, brevemente, as etapas que caracterizam a aplicação do jogo de contar histórias.

\subsection{Mecânica do jogo de contar histórias}

\section{a) Escolha do tema}

O primeiro passo para a realização do jogo consiste na escolha de um tema central. A definição do tema tem como objetivo criar uma unidade narrativa para a história, visto que o tema atua como um limitador para outros elementos que serão criados a partir dele nas etapas seguintes. O tema pode ser escolhido previamente pelo professor ou pode ser escolhido com o auxílio da turma: por exemplo, lista-se no quadro-negro várias possibilidades de tema e realiza-se uma votação para definir uma delas.

\section{b) Montagem da tabela de universo ficcional}

No quadro-negro, o professor cria uma tabela com quatro colunas. Cada coluna contém uma lista de personagens, objetos, lugares e acontecimentos. Com o auxílio de toda a turma, a tabela vai sendo preenchida. O número de itens de cada coluna deve coincidir com o número de integrantes de cada um dos grupos formados. A seguir apresentamos um exemplo de tabela (Tabela 1) montada com o tema "ecologia". 
6

Tabela 1 - Exemplo de uma tabela de universo ficcional

\begin{tabular}{|c|c|c|c|}
\hline \multicolumn{4}{|c|}{ Tema: ecologia } \\
\hline Personagem & Objeto & Lugar & Acontecimento \\
\hline caçador & caminhão & floresta & explosão \\
\hline lenhador & espingarda & praia & incêndio \\
\hline índio & binóculo & escola & acidente de carro \\
\hline fiscal do IBAMA & $\begin{array}{l}\text { barril de } \\
\text { petróleo }\end{array}$ & aldeia & manifestação/passeata \\
\hline estudante & explosivos & empresa de mineração & tsunami \\
\hline empresário & machado & cidade & vazamento de óleo \\
\hline
\end{tabular}

c) Divisão da turma em grupos

A turma é dividida em grupos de, no máximo, seis integrantes.

\section{d) Escolha e apresentação de um personagem}

Todos os grupos consultam a mesma tabela de universo ficcional. Cada integrante do grupo escolhe um dos personagens da tabela e o apresenta aos demais colegas. Deve ser atribuído ao personagem um nome e também características físicas, psicológicas, dentre outras que auxiliem os outros integrantes do grupo a melhor imaginá-lo.

\section{e) Escolha de um objeto, um acontecimento e um lugar}

Em seguida, cada grupo escolhe um objeto, um acontecimento e um lugar. Esses elementos deverão aparecer necessariamente na narrativa. $\mathrm{O}$ grupo debate sobre como esses elementos irão aparecer, qual a sua importância etc.

\section{f) Escolha de um assunto principal}

A escolha por um assunto principal visa gerar um ponto de afunilamento em torno do qual a história se desenvolverá. A definição do assunto principal ocorre através da escolha de um dos elementos da tabela (excetuando-se a coluna de personagens). A escolha pode, ainda, ser realizada de forma aleatória: jogando-se dados ou através de sorteio.

\section{g) Escolha de um redator}

Um integrante do grupo deve ser escolhido para anotar os principais acontecimentos narrados, tendo em vista gerar um registro para consulta posterior. Sugere-se que a escrita ocorra na forma de uma lista de tópicos e não na forma de redação, tendo em vista tornar mais ágil o processo.

\section{h) Jogando o jogo}

Depois de explicadas as regras, os grupos iniciam a sessão do jogo. Primeiramente, escolhe-se quem deve começar a narrar a história. Um critério para a escolha pode ser, por exemplo, iniciar com o integrante mais velho do grupo. Este então tem até três minutos para narrar o início da história. Após esse período, a função de narrador deve ser passada a um outro aluno, e assim por diante até que se completem duas rodadas, chegando-se ao final da dinâmica.

Enquanto um aluno narra, os outros devem respeitá-lo sem interromper sua fala. Contudo, é permitido que o grupo aponte sugestões de como a história pode avançar, principalmente se o aluno que está no comando da narração estiver com dificuldade. 
Assim, os demais alunos poderão interagir ${ }^{7}$

durante a narração, dando uma fluidez maior à história. Ainda, ao narrar uma cena, o aluno pode optar por incluir qualquer personagem que esteja no quadro.

A seguir, relatamos o processo de aplicação do jogo de contar histórias com alunos de ensino fundamental e médio.

\section{Aplicação do jogo de contar histórias}

O jogo de contar histórias foi aplicado, pela primeira vez, na manhã do dia 14 de abril de 2012, durante uma oficina de produção literária, realizada como parte das atividades do projeto Sábado Letivo, que ocorre mensalmente na Colégio Estadual Dr. Wolfram Metzler. A atividade contou com a participação de 26 alunos de turmas da sétima série ao terceiro ano do ensino médio.

Inicialmente, foi apresentado aos alunos uma descrição geral da atividade e também de jogos no estilo RPG, com a finalidade de compartilhar com o grupo o contexto em que a dinâmica foi criada. Em seguida, realizou-se o processo de escolha do tema, que nesta ocasião foi "o fim do mundo", e também o preenchimento da tabela de universo ficcional. A etapa seguinte foi a divisão da turma em grupos de cinco integrantes, sendo que um dos grupos ficou com um integrante a mais. Passado esse momento, foi dado início ao jogo, conforme as etapas descritas na seção anterior.

Após a sessão do jogo, os alunos produziram, individualmente, uma redação a partir da história narrada pelo seu grupo. Para tanto, puderam consultar as anotações feitas pelo redator do grupo durante o jogo. Ao final da oficina, os textos foram entregues ao grupo do PIBID para posterior avaliação. ${ }^{12}$

\subsection{Avaliando a atividade}

No que se refere ao primeiro momento da atividade, em que foram apresentadas a descrição do jogo e de temas relacionados ao contexto em que o mesmo foi elaborado, percebeu-se que a maior parte dos alunos se mostraram atentos e interessados, principalmente aqueles que já haviam tido um contato anterior com jogos de RPG. O interesse se mostrou também no momento de escolha do tema e preenchimento da tabela de universo ficcional.

Contudo, alguns problemas foram percebidos logo no início da etapa posterior à divisão dos grupos, quando os alunos deveriam então começar a se preparar para o início do jogo. A primeira dificuldade apresentada por vários alunos foi o não entendimento de algumas regras. Na hora de jogar, muitos não sabiam o que fazer e reclamaram do nível de dificuldade da atividade.

Também o modo como alguns alunos escolhiam os elementos da tabela de universo ficcional se mostrou problemático: ao invés de buscarem combinações entre os diversos níveis da tabela, tendiam a realizar escolhas lineares, isto é, combinando o personagem aos demais elementos da mesma linha. Uma hipótese para explicar por que a escolha tenha se dado dessa maneira pode estar relacionada com a própria forma da tabela, que organiza os elementos linearmente.

Quanto ao andamento do jogo em si, observou-se que, em alguns grupos, o papel do narrador não era respeitado e todos procuravam dar sua opinião e escolher os acontecimentos juntos, o que acabava por gerar tumulto e perda do foco na atividade. Alguns alunos se valiam desses momentos para se absterem de participar da atividade, abrindo mão de sua vez como narrador para que outros, mais engajados na atividade, exercessem essa função em seu lugar.

Outro problema percebido foi em relação à função de redator que deveria ficar responsável pela escala de eventos, anotando-os em tópicos. Em pelo menos dois dos 
grupos foi observado que o narrador, ao

invés de realizar o registro através de tópicos, preocupava-se em desenvolver o texto com alto nível de detalhamento. Dessa forma, pulava-se uma etapa do processo, visto que a função do jogo seria justamente incentivar a criação coletiva da narrativa, sendo a escrita do texto uma etapa posterior à sessão. Além disso, o processo de narração se tornava mais lento, levando-se em conta que a escrita é mais vagarosa que o processo de criação oral, gerando atraso e perda do interesse de alguns alunos, que logo se aborreciam de esperar o redator terminar de anotar uma cena narrada.

Como as turmas eram de séries diferentes, procurou-se integar os alunos, misturando-os em diferentes grupos. Contudo, os alunos do ensino médio não se integraram com os alunos de sétima e oitava séries, o que ocasionou certa inibição por parte dos mais novos, que, em alguns momentos, demonstraram dificuldades em ter ideias e expressar suas opiniões frente aos mais velhos.

\section{Encaminhamentos para ajustes e alterações na mecânica do jogo de contar histórias}

Na tarde do dia 19 de abril de 2012 a atividade foi aplicada novamente, também com 26 alunos, porém, de uma mesma turma de primeiro ano do ensino médio da mesma escola. Nessa ocasião, alguns ajustes na metodologia da atividade foram efetuados, tendo como base a avaliação realizada sobre a experiência anterior.

As regras não foram explicadas de uma só vez: cada etapa era explicada e sucedida pela sua aplicação prática. Dessa maneira, ainda que os alunos não tivessem acesso imediato ao conjunto de regras e partes da atividade, a compreensão se deu gradualmente, facilitando, inclusive, o processo de esclarecimento de eventuais dúvidas que surgiam a cada momento.

Quanto à escolha dos elementos, optou-se por não desenhar no quadro-negro a tabela de universo ficcional, pois, conforme mencionado, alguns alunos buscavam relacionar linearmente os elementos, isto é, escolhiam o objeto, acontecimento e lugar por estarem situados na mesma linha que o personagem, ao invés de buscar outros tipos de associação. A estratégia utilizada foi a de desenhar círculos separados por intervalos, de modo a tornar mais difícil o processo de associação linear. Essa técnica resultou em uma maior fluidez na escolha dos elementos.

Para reforçar a função de narrador que cada aluno deveria ocupar, foi confeccionado um cartão, que deveria ficar sob posse de quem estivesse narrando. Os demais só poderiam interromper a narração com a permissão do narrador. Esse recurso mostrou-se eficiente, pois o cartão ajudou a sinalizar, visualmente, quem estava com o comando da narrativa.

Quanto aos problemas encontrados com a função de redator do grupo, a estratégia adotada foi apenas de reforçar o papel do redator de tomar nota dos principais acontecimentos em forma de tópicos, enfatizando que a escrita do texto seria realizada individualmente em um momento seguinte e não na hora de jogo.

\section{Considerações finais}

O uso de mecânicas e elementos de jogos em sala de aula ainda se mostra como um vasto território a ser desbravado por aqueles que se dedicam buscar formas inovadoras de ensino-aprendizagem. Jogos de RPG, quando bem aplicados em atividades de ensino, estimulam uma visão sistêmica dos acontecimentos experimentados na forma de jogo. Além disso, incentivam a imaginação dos alunos, ativando o processo de criação, seja científico ou artístico, possibilitando formas de apresentação do conteúdo não através de uma didática árida, mas dentro de um conjunto 
rico. O trabalho em grupo é um outro

aspecto positivo, colocando os alunos em constante interação e promovendo o espírito colaborativo entre eles ao invés de competição.

Neste texto, abordamos o processo de pesquisa e elaboração de uma técnica para criação de histórias colaborativas em atividades de sala de aula. Como ponto de partida, apresentamos algumas experiências relatadas por professores que aplicaram técnicas de RPG com diferentes propostas de ensino-aprendizagem. Em seguida, analisamos algumas dificuldades encontradas no processo de transposição das regras e das dinâmicas de RPGs para o contexto escolar. Com isso, apresentamos, na terceira seção, o processo de pesquisa efetuado sobre jogos que estimulam o compartilhamento da função narrativa entre seus participantes. Com base nesses estudos preliminares, relatamos nossa própria experiência de formulação e aplicação de uma técnica baseada no princípio de colaboração entre os alunos no processo de criação de histórias.

Em termos gerais, consideramos que o uso da técnica de jogo de contar histórias se mostrou eficiente em relação ao objetivo de gerar interesse e facilitar o processo de produção textual em atividades de redação. Cabe destacar que ao final da segunda vez em que atividade foi aplicada, realizamos uma avaliação informal com os alunos, buscando compreender o nível de satisfação destes com a experiência e também identificar o quanto o jogo auxiliou na produção textual. Segundo relatos de alguns participantes, foi mais fácil desenvolver o texto escrito após a sessão do jogo, pois os elementos e os fatos já estavam estabelecidos e só precisavam ser organizados na forma de redação.

Todavia, consideramos também que o preparo do professor em relação ao ensino das regras é de extrema importância para a aplicação da técnica. Conforme relatamos, ainda que a mecânica do jogo de contar histórias tenha sido elaborada com foco na simplicidade, ainda assim os alunos demonstraram, na primeira vez em que foi aplicada, dificuldades em compreendê-la. Assim, com alguns ajustes efetuados tanto na mecânica em si quanto no modo de apresentá-la, houve uma melhora significativa na dinâmica da atividade, que se tornou mais organizada.

Dessa maneira, concluímos que, mesmo que o processo de ajuste nas regras de funcionamento do jogo de contar histórias não tenha sido concluído, o caminho aberto por essas duas experiências iniciais de aplicação da atividade fornece motivação para continuarmos a realizar novos testes e propor outras formas de criar histórias coletivas em sala de aula.

1 Neste artigo, os termos "jogo de interpretação" e "role-playing game" são usados como sinônimos, sendo o primeiro a tradução para o português do segundo.

2 O Colégio Estadual Dr. Wolfram Metzler está localizada na cidade de Novo Hamburgo, no Rio Grande do Sul.

3 Alunas bolsistas do PIBID: Tatiane Schuster e Caterine Schneider - coordenação: Prof $^{a}$ Me. Maria Helena Albé. Alunos do GENI: Tiaraju Fisch e Wyllian Hossein coordenação: Prof. Me. Tiago R. C. Lopes.

4 Os RPGs podem ser definidos, sucintamente, como jogos nos quais os personagens, que são criados e controlados pelos participantes do jogo, participam de histórias que evoluem sob o comando de um narrador, também chamado de "mestre".

5 Tese de Doutorado defendida em 1997 que deu origem ao livro Roleplayng game e a pedagogia da imaginação no Brasil, publicado pela editora Bertrand Brasil, em 2004.

6 Em 2011, transcorridos onze anos desde a realização do I Simpósio RPG e Educação, foi publicado um livro apresentando os anais do evento. 
10

7 Segundo a perspectiva apresentada por Pereira e Bettocchi (2008), no contexto dos jogos no estilo RPG o conceito de "jogo" é problematizado, uma vez que não há propriamente competição, mas cooperação entre os jogadores, que interpretam seus personagens e constroem a narrativa de forma colaborativa. É também nesse sentido que propomos, neste artigo, o uso da palavra "jogo" para dar título à técnica de construção de narrativas em grupos, a qual denominamos de "jogo de contar histórias".

8 Vinculado ao curso de graduação em Jogos Digitais da Universidade do Vale do Rio dos Sinos (UNISINOS), o Grupo de Estudos em Narrativas Interativas (GENI) reúne alunos de diversas graduações - Jogos Digitais, Letras, Comunicação Digital, Educação Física, dentre outras - em pesquisas e projetos voltados à reflexão sobre os modos de participação dos sujeitos em contextos que envolvam a produção e o consumo de narrativas. Para mais informações sobre o GENI, acesse: <http://geniunisinos.wordpress.com>

9 Histórias geradas em grupo e que apresentam como principal característica o compartilhamento da função narrativa entre os participantes.

10 Três corvos, três homens mortos é uma tradução do jogo original Three black crows, three dead men, escrito por Brennan Taylor. Fiasco foi escrito por Jason Morningstar, tendo sido publicado em português pela editora RetroPunk, em 2011. $O$ jogo dos espíritos, escrito por Tiago Jungs, foi lançado de forma independente em 2011.

11 Para mais informações sobre Violentina, acesse: <http://www.seculargames.com/tag/violentina/>

12 Vale ressaltar que, no espaço deste artigo, não analisaremos o conteúdo dos textos, ainda que seja este um tema de interesse para trabalhos futuros.

\section{Referências bibliográficas}

AZEVEDO, Leandro. 10 Atividades de RPG Educacional para o Ensino de História. 2007.

BETTOCCHI, Eliane ; PEREIRA, Carlos. Escrita e leitura através de narrativas e livros interativos. In: COELHO, Luiz Antônio; FARBIARZ, Jackeline Lima; FARBIARZ, Alexandre. (Org.). Os lugares do Design na leitura. 1 ed. Teresópolis.: Editora Novas Ideias, 2008, v. 1, p. 149-196.

COELHO, Luiz. (Org.). Os lugares do design na leitura. Teresopolis: Novas Ideias, 2008.

FREIRE, Paulo. Pedagogia da autonomia. São Paulo: Paz e Terra, 2006.

GRANDO, Anita; TAROUCO, Liane. O uso de Jogos Educacionais do tipo RPG na educação. RENOTE. Revista Novas Tecnologias na Educação, v. 6, p. 1-10, 2008.

KISHIMOTO, Tizuko Morchida. O jogo e a educação infantil. São Paulo: Livraria Pioneira Editora, 1994.

PEREIRA, Carlos. TNI (Técnicas para Narrativas Interativas). Boletim Técnico do

SENAC, v. 33, p. 72-85, 2008. 
SILVEIRA, Fabiano; COSTA, Antônio. RPG na sala de aula: criando um ambiente lúdico para o ensino da língua inglesa. Anais do Fórum Internacional de Ensino de Línguas Estrangeiras, Pelotas, RS, 2004.

VYGOTSKY, Semenovitch. A formação social da mente. Martins Fontes, 1994. 